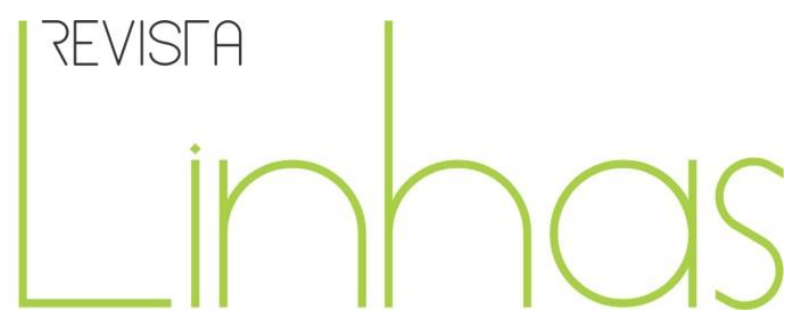

\title{
De jardineira para a jardineira: orientações didático- pedagógicas para a educação pré-primária (Revista do Ensino/RS, 1951-1963)
}

\begin{abstract}
Resumo
O presente artigo analisa a seção "Educação Pré-Primária", da Revista do Ensino/RS, especialmente a subseção "De Jardineira para a Jardineira", espécie de lembrete cotidiano à professora de educação infantil, nos anos 1950 e 1960. Além desse tópico, eram publicados textos sobre a educação da criança, modelos de atividades para os alunos (perfuração, alinhavos, dobraduras, modelagem, trançado, jogos), indicação de livros para professores e alunos, planos de aula, relatos de experiência, músicas, peças de teatro, assim como posturas e qualidades que o docente deveria apresentar (decálogos). O estudo permite verificar tanto a presença de um discurso articulado de construção da identidade da professora jardineira, pela sacralização de sua função, como um discurso sobre o jardim de infância como espaço de preparação da criança para o processo de alfabetização na escola primária. Ao privilegiar como fonte e objeto de estudo a imprensa de educação e ensino, o estudo indica sua importância tanto como veículo de produção e circulação de representações da vida educacional e escolar, quanto como dispositivo de formação continuada de professores.
\end{abstract}

Palavras-chave: Jardim de Infância. Educação de Crianças - História. Educação Pré-Escolar. Professores de Educação Pré-Escolar. Revista do Ensino - Rio Grande do Sul.

\author{
Maria Helena Camara Bastos \\ Pontifícia Universidade Católica \\ do Rio Grande do Sul - PUC/RS - \\ Brasil \\ mhbastos@pucrs.br
}

\footnotetext{
Para citar este artigo:

BASTOS, Maria Helena Camara. De jardineira para a jardineira: orientações didático-pedagógicas para a educação pré-primária (Revista do Ensino/RS, 1951-1963). Revista Linhas. Florianópolis, v. 18, n. 38, p. 63-80, set./dez. 2017.
} 


\title{
From a kindergarden teacher to the kindergarden teacher: didactical-pedagogical guidance for pre-school education (Revista do Ensino/R, 1951-1963)
}

\begin{abstract}
This article analyzes the section on "Pre-School Education" in the Revista do Ensino/RS, especially the subsection." From a Kindergarden teacher to the Kindergarden teacher", a kind of daily memo to the teachers of infant education in the 1950 s and 1960 s. Besides this topic, texts were published on child education, models of activities for the pupils (making holes, stitching together, folding, modeling, pleating, games), suggesting books for teachers and pupils, lesson plans, reports on experiences, music, plays, and also attitudes and qualities the teacher should present (decalogues). The study allowed to verify both the presence of an articulated discourse on construction of the kindergarden teacher's identity by giving a hallowed status to their function, and also a discourse on kindergarden as the space to prepare the child for the process of learning literacy in elementary school. By privileging the press on education and teaching as source and object of study, the study indicates its importance both as a vehicle for the production and circulation of representations of the educational and school life, and as a device for continuous teacher training.
\end{abstract}

Keywords: Child Education - History. Preschool Education. Preschool Teacher Education. Revista do Ensino (the journal on education for teachers in the state of Rio Grande do Sul). 


\section{Introdução}

A Revista do Ensino/RS (1951-1978)', como dispositivo de finalidades educativas, procurou ser um guia à educadora jovem e idealista, encontrando em suas páginas "a solução para resolver os árduos, porém sublimes, problemas do seu mister" e orientações/sugestões sobre como desempenhar suas funções. Buscou ser um instrumento técnico-pedagógico de atualização permanente dos professores em serviço e dos alunos das escolas normais, através da divulgação de experiências pedagógicas, da realidade da educação e do ensino, como apoio ao conteúdo das diferentes áreas que compunham o currículo do ensino.

O periódico foi uma publicação oficial da Secretaria de Educação e Cultura/RS, sob a supervisão técnica do Centro de Pesquisas e Orientações Educacionais - CPOE/RS (1951$1971)^{2}$. Instrumentalizava a professora na execução da atividade docente, através de fartos recursos visuais e sugestões variadas, com a publicação de suplementos didáticos ${ }^{3}$. Como instância de produção e de circulação dos saberes escolares, o periódico é uma fonte privilegiada para a escrita da história da educação infantil.

Entre as inúmeras seções do sumário, a seção Educação Pré-Primária está presente desde o número 1, de setembro de 1951, mas não apresentava continuidade. A partir de março de 1954 ( $n^{\circ} 20$ ), aparece em todos os números, mantendo-se assim até agosto de 1961 ( $n^{\circ} 77$ ), quando se divide em duas subseções - Fundamentos da Educação (Textos teóricos, De Jardineira para Jardineira) e Direção da Aprendizagem (orientação de atividades de Linguagem, Música e Canto, Iniciação à Matemática, Recreação e Jogos, Artes, Teatro), que compreendem um conjunto variado de atividades práticas formais para o cotidiano das crianças.

Nesse período histórico, a educação pré-primária se intitulava “Jardim de Infância", atendendo crianças de 4 a 6 anos. As professoras desse nível eram chamadas

\footnotetext{
${ }^{1}$ Em seus vinte e seis anos, a revista publicou cento e setenta (170) números, com oito a dez números anuais, com uma média de 80 (oitenta) páginas de material informativo didático-pedagógico. Com uma tiragem inicial de 5.000 exemplares, atingiu a marca de 50.000 exemplares, no início da década de 60 . A tiragem é um significativo indicador da repercussão da revista no meio educacional - regional, nacional e internacional -, muitas vezes único meio de (in)formação à disposição do professor e de utilização na sua prática cotidiana. Sobre a Revista do Ensino/RS, ver BASTOS (1997, 2005, 2009).

${ }^{2}$ Sobre, ver QUADROS (2000), PERES (2005).

${ }^{3}$ Sobre, ver BASTOS, LEMOS, BUSNELLO (2007).
} 
“jardineiras”4. O número 4 publica uma síntese de como os editores caracterizavam o Jardim de Infância e a tônica que seria dada na seção de Educação Pré-primária, envolvendo professora e crianças:

O Jardim de Infância deve ser um prolongamento do lar, e, para que a jardineira consiga atrair as crianças ao Jardim é preciso observar o seguinte: a jardineira deve ser agradável, cortês, delicada, calma e de aparência atraente; a sala do jardim deve ser ampla, clara, bem arrumada, bem limpa, ornamentada com vasos de flores ou plantas para dar ao ambiente uma impressão agradável e atraente; todos os objetos devem ter lugar apropriado, a fim de que desperte e desenvolva na criança o hábito da ordem e da arrumação; o material deve ser variado para que as atividades a proporcionar às crianças favoreçam seu desenvolvimento físico, intelectual, social e emocional; várias atividades podem ser desenvolvidas no Jardim - a música, o desenho, o modelado, o recorte, as artes representativas em geral, as dramatizações, as projeções luminosas, o teatro infantil. (REVISTA DO ENSINO/RS, n. 4, mar. 1952, p. 26)

Neste texto, pretende-se tomar como foco a seção "Educação Pré-Primária", especialmente a subseção identificada no sumário “De Jardineira para a Jardineira", espécie de "lembrete" cotidiano à professora. Além desse tópico, eram publicados textos sobre a educação da criança, modelos de atividades para os alunos (perfuração, alinhavos, dobraduras, modelagem, trançado, jogos), indicação de livros para professores e alunos, planos de aula, relatos de experiência, músicas, peças de teatro, assim como posturas e qualidades que o docente deveria apresentar (decálogos).

Uma preocupação constante na trajetória editorial do periódico foi com a valorização “simbólica” do trabalho docente, através de poesias, mensagens, artigos, pensamentos, credos, Orações à Mestra, distribuídos por suas páginas, enaltecendo a prática educativa e prescrevendo um modelo de atitudes e condutas ao professor e ao aluno. Por exemplo, para a educação pré-primária, “Os Dez mandamentos da Educação Infantil”, publicados no jornal Correio do Povo, em 10 de julho de 1957, são reproduzidos na Revista do Ensino/RS:

\footnotetext{
${ }^{4}$ Só na década de 1950 que começam a serem ministrados os primeiros cursos para professoras jardineiras em Porto Alegre, no Instituto de Educação Gen. Flores da Cunha, que exigia o curso Normal completo e durava dois anos. Desde 1929, a Escola Normal mantinha um Jardim de Infância. Sobre, ver LOURO (1986); SOUZA (2000).
} 
1. Não digas a uma criança "Não faça isso";

2. Não digas que uma coisa é "má", apenas porque ela te aborrece;

3. Não fales das crianças em sua presença, nem penses que elas não escutam, não observam e nem compreendem;

4. Não interrompas o que uma criança está fazendo sem avisá-la previamente;

5. Não demonstre inquietação quando a criança cai, ou não quer comer, faça o que for necessário sem agitares e alarmares;

6. Não demonstre seu amor pela criança acariciando-a constantemente. Faze-o ocupando-te de seus interesses;

7. Não leves uma criança a passeio, e sim vá passear com ela;

8.Não faça sermões morais à criança pequena;

9.Não falte às tuas promessas, nem prometa o que não podes cumprir;

10. Não minta para uma criança.

(Revista do Ensino/RS, (n 57 , nov. 1958, p. 14)

Outro exemplo volta-se diretamente para prescrever as atitudes ideais da jardineira, como "Os 10 Mandamento por uma Jardineira”, de Gisela Schmelling 5 , o que qualificava o dito. Recomendações relativas ao silêncio, à voz baixa são tanto para o professor como para o aluno. Ao professor, destacava-se que deve ter muita perseverança na sua atuação; dar ordens afirmativas, evitando o uso constante do "não"; ocupar constantemente os alunos; preparar as atividades antecipadamente, graduandoas de acordo com o grau de desenvolvimento da criança.

1. Nunca levante a voz;

2. Seja perseverante na Educação;

3. Procure ser consequente nas suas ordens;

4. Verifique se todos seus alunos estão sempre ocupados;

5. Procure graduar os exercícios;

6. Torne a criança responsável pelo brinquedo que usou e procure fazê-lo compreender o motivo;

7.Procure apaziguar brigas sem castigos se o motivo for fútil;

8. Exija absoluto silêncio durante a hora do repouso;

9. Aproveite toda a oportunidade para favorecer e ampliar o vocabulário e a linguagem dos pequenos;

10. Nunca prepare trabalho em sala de aula.

(Revista do Ensino/RS, n 11, nov. 1952, p. 19)

\footnotetext{
${ }^{5}$ A professora publica várias orientações de atividades para os jardins de infância. Sobre Gisela Schmelling, ver BASTOS (2016).
} 
Esse decálogo faz parte de uma estratégia discursiva adotada pelo impresso para orientar a formação e prática das "professoras pré-primárias", que deviam, segundo Évrard-Fiquemont (1963), em primeiro lugar:

amar profundamente os pequenos, o que supõe certos dotes inatos: dom de si, abnegação, dedicação, paciência; gozar de boa saúde e ter nervos equilibrados, aparência agradável, voz suave, igualdade de humor, alegria serena, bom gosto, demonstrar uma autoridade natural e um grande domínio de si, ser justa, firme e boa. Dotada de espírito curioso, inquiridor e aberta às ideias gerais, possuir um juramento são, discernimento, espírito de observação, numa palavra senso psicológico. Ser professora de Jardim de Infância é um dom que se desenvolve, mas não se adquire. (apud SOUZA, 2000, p.142-43)

A tradução e adaptação do artigo escrito por Martha Koire, intitulado "Requisitos para uma Professora de Jardim de Infância", também é um expressivo exemplo das expectativas esperadas da professora jardineira pela equipe editorial:

Ter paciência, alguns conhecimentos médicos, ser formada em Educação, ser hábil transportadora de móveis, ser arrumada, ser boa dona de casa, ser razoável marceneira, ser psicóloga, ser "artista" (e pianista se possível). Deve ter também uma excelente visão (para ver os 4 cantos ao mesmo tempo), saber voar (ultrapassar com facilidade os muitos obstáculos espalhados pela sala), correr mais rápido do que uma lebre (para estar presente onde e quando for necessário), andar suavemente para passar tranquilidade, cantar e dançar com alegria e olhar para cada criança como uma criança e as crianças como um grupo. (KOIRE, 1961, p. 34)

A listagem das qualidades e habilidades necessárias, destacadas em negrito ${ }^{6}$, definem um perfil profissional ideal e idealizado de ser docente, o que não reflete ou explica o docente que realmente existiu, mas assume a função de espelho na qual o professor deveria buscar sua imagem. Paralelo a esta intenção, constitui-se também um conjunto de falas relativas às normas e aos valores de conduta profissional como forma de controle da profissão docente (BASTOS; COLLA, 2004).

\footnotetext{
${ }^{6}$ Negritos da pesquisadora.
} 
A autora sugere ainda que as professoras jovens precisam ir devagar quando observam o grupo e recomenda: "sua melhor atitude é observar, esperar para dar auxílio, não se precipitar na ajuda da criança e deixar tanto quanto possível a criança fazer e descobrir". Além de todo discurso prescritivo, o artigo explicita que a professora jardineira deveria "possuir conhecimentos sólidos de psicologia infantil e de didática especial para atuar com as crianças".

\section{De jardineira para jardineira: 1956-1963}

Esta subseção iniciava sempre a parte destinada à Educação pré-primária, a partir do número 36, de março de 1956, ocupando espaços reduzidos no alto das páginas e/ou em quadros destacados ${ }^{7}$. Em agosto de 1961, quando a seção Educação Pré-primária se subdivide em duas, passa a integrar a subseção Fundamentos da Educação, permanecendo até agosto de 1962 ( $n^{\circ}$ 85), quando deixa de ser publicada. Acompanhava esta subseção a indicação de “Livros para a biblioteca de uma Jardineira” (Educação Préprimária), como observamos na imagem abaixo.

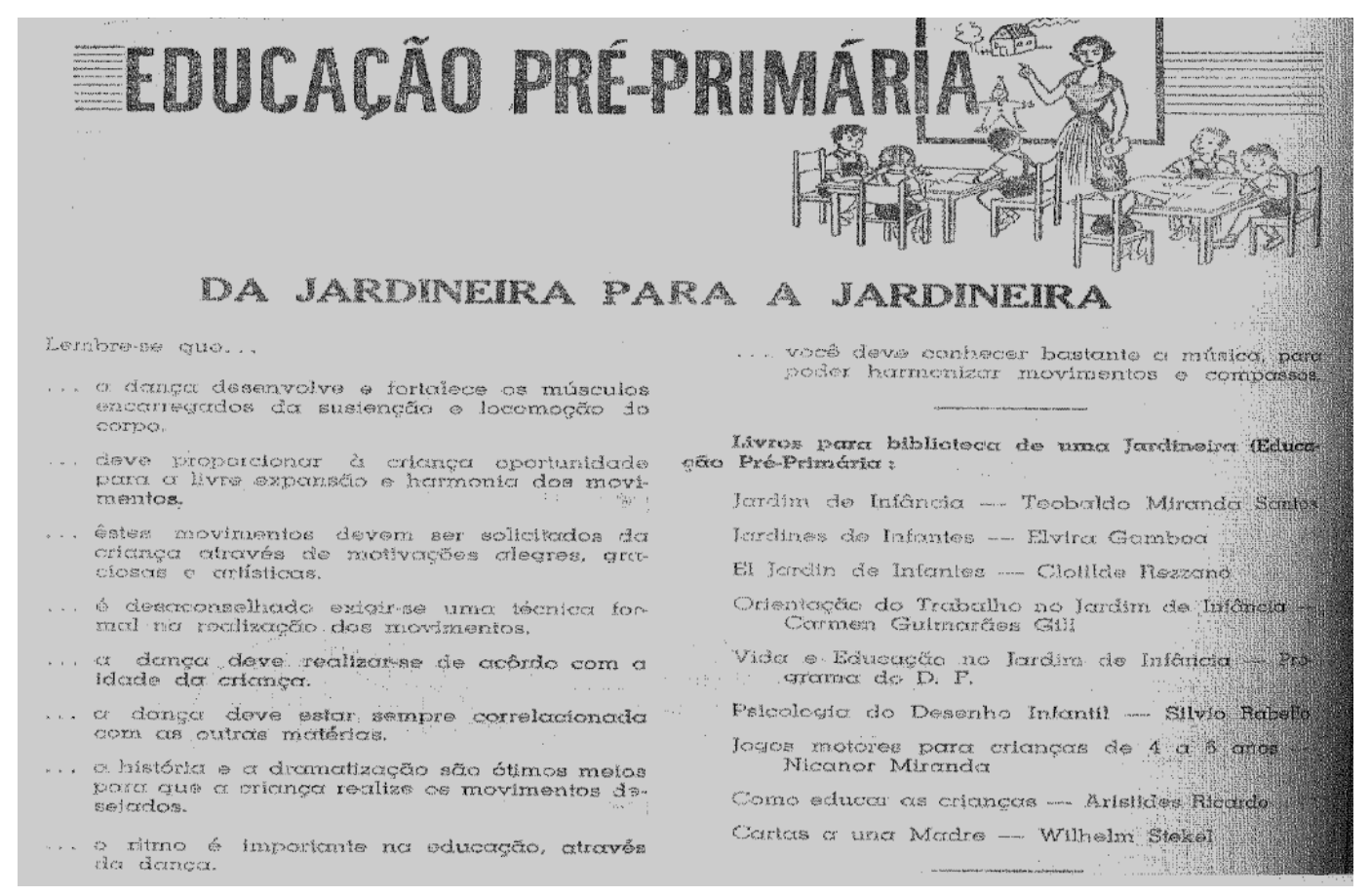

Figura 1: Educação Pré-Primária

Fonte: REVISTA DO ENSINO/RS, n 61, junho 1959, p. 20.

\footnotetext{
${ }^{7}$ De outubro de 1958 ( $n^{\circ}$ 56) a junho de 1959 ( $n^{\circ}$ 61) não são publicados esses lembretes.
} 
No levantamento efetuado, a seção esteve presente em 33 números, o que permitiu fazer uma tabulação dos temas abordados, os quais podem ser divididos em dois conjuntos: um relativo às temáticas voltadas a orientar a atuação pessoal e profissional da professora jardineira no cotidiano escolar (as qualidades da jardineira quanto à voz, à reflexão é uma qualidade, a autonomia, a integração da criança ao grupo). O outro, reúne os temas relativos ao desenvolvimento e aplicação das atividades práticas com as crianças (modelagem, pintura com os dedos, o desenho, os brinquedos, a música) (Quadro 1, anexo).

Esta subseção não trazia a identificação de autoria, no entanto, podemos pensar que as responsáveis pelos lembretes eram as professoras primárias Eloah Brodt Ribeiro, Gilka Niederauer Fontoura, Ester Malamut, que colaboravam em todos os números com a seção destinada à Educação Pré-primária. Somente no número 93 (jun. 1963, p. 22) aparece um lembrete que destaca a autoria, no caso, a professora Gilda Garcia Bastos, da equipe da revista ${ }^{8}$. Outra pista, é que essa seção fosse de responsabilidade da professora Gladys Hadda Correa Vieira, responsável pelo setor Pré-Primário do CPOE/RS. Em "Sugestões para o desenvolvimento de atividades nos Jardins de Infância IV, elaborado por Eloah Brodt Ribeiro e Gilka Niederauer Fontoura, há a reprodução de uma pequena mensagem assinada por ela, em que chama a atenção de que o que é publicado na revista “resulta de atividades executadas, com resultado, pelas professoras Jardineiras" e apela para que outras colaborem com o periódico, "para que possamos tomar esses subsídios um trabalho de professora jardineira para as professoras jardineiras" (Revista do Ensino/RS, $n^{\circ} 75$, abr. 1961, p. 50).

É interessante assinalar que muitos dos lembretes qualificam as orientações, ressaltando "Lembretes de professora pré-primária para outras professoras préprimárias", ou seja, uma colega orientando outra colega. O próprio título remete para essa ideia. Além dessa estratégia discursiva, em alguns números, no pé de página, havia um chamado intitulado "Cantinho da Educadora", em que eram publicados pensamentos de autores estrangeiros, como estímulos à reflexão das leitoras:

\footnotetext{
${ }^{8}$ Outros textos da seção Educação Pré-primária, especialmente os que integram a seção Fundamentos da Educação, escritos por professoras gaúchas sempre trazem a identificação da autoria.
} 
"Somente quem se ajeita a brincar com as crianças pode the ensinar alguma coisa", Mme de Stäel;

"A verdadeira vida da infância é ao ar livre. Mesmo nas cidades, cumpre quando possível associá-la ao mundo vegetal", Michelet;

"Eu vejo em cada criança a possiblidade de um homem perfeito", Gladestone;

"A família é a base da Educação", Angelo Patri;

"Só é um bom observador aquele que consegue observar minuciosamente sem ter observado", Johan Casper Lavater. (REVISTA DO ENSINO/RS, $n^{\circ} 77$, ago. 1961, p. 31)

De Jardineira para a Jardineira começava sempre com a expressão - Lembre-se que... e seguiam-se tópicos iniciados com “... a educação física ocupa papel importante no período pré-primário" (REVISTA DE ENSINO/RS, n 74, mar. 1961). Alguns alertas aos professores iniciavam com Você não esqueceu que... e a seguir uma lista de deveres e atividades a serem lembrados, como no exemplo abaixo, retirado do "Programa de Atividades", da Secretaria Geral de Educação e Cultura, do Distrito Federal:

Deve globalizar as atividades, no sentido de economizar esforço?; deve estar sempre em condições de, pela sua presença e atuação, controlar as situações que surjam?; deve manter a ordem sem rigidez (flexibilidade de horário)?; deve dar ordens afirmativas e evitar as negativas?; deve usar um tom suave e persuasivo de voz?; deve agir tendo sempre em vista as diferenças individuais?; deve ter habilidade em orientar a aquisição de hábitos fundamentais? (REVISTA DO ENSINO/RS, n³7, abr. 1956, p. 9)

Esta listagem em forma de perguntas, orienta a reflexão que a professora jardineira deveria estar sempre atenta. Nessa mesma direção, é o emblemático lembrete de que toda pessoa necessita, de vez em quando, fazer um exame de consciência (pessoal e profissional), um balanço de suas atividades, especialmente, uma educadora - "a reflexão é uma qualidade indispensável a qualquer educador"; “toda pessoa necessita de vez em quando fazer um exame de consciência, um balanço de suas atividades". A orientação, dada em 13 itens, inicia com um exame do ponto de vista físico, "sua saúde deve ser boa, sua aparência agradável e atraente; ser calma e bem-humorada". A seguir, um levantamento de seu preparo técnico, que envolve a atualização no campo da educação: ler bons livros; assistir conferências; frequentar cursos de aperfeiçoamento; 
revisar, renovar e melhorar o material didático que utiliza em sala de aula (Revista Do Ensino/Rs, nº6, mar. 1960, p. 28).

As prescrições se repetem em números alternados, tanto no aspecto comportamental da docente quanto nas atividades didático-pedagógicas que devem proporcionar às crianças. É recorrente, por exemplo, chamar a atenção de que deve "conduzir seus ensinamentos através de situações reais - viver a vida -, prepará-la para o dia de amanhã". A observação, a experiência e a diversidade de atividades, seguindo os princípios da pedagogia ativa, são requisitos fundamentais no cotidiano.

A seção também visava instrumentalizar a professora para proporcionar múltiplas atividades: desenho, pintura, recortes, trabalhos de colagem, modelagem, confecção de quadros, construções com blocos, conversas informais, entrevistas, reportagens, histórias, dramatizações, adivinhações, rimas, poesias, hora do rádio e da televisão, consideradas "meios que desenvolvem e aprimoram a expressão criadora da criança", dispositivos a serem explorados para a linguagem oral e o desenvolvimento de seu vocabulário (REVISTA DO ENSINO/RS, n61, set. 1961, p. 10).

Assim como são constantemente normatizadas as atitudes e comportamentos das professoras jardineiras, o aluno também é foco das orientações dadas, a partir de listagem de hábitos e atitudes a desenvolver nas crianças.

Lembre-se, cabe às jardineiras proporcionar as crianças:

Aquisição de hábitos higiênicos, de ordem, de disciplina, de assiduidade e pontualidade, de segurança, de polidez, de cooperação, de respeito, de independência, de sociabilidade;

A formação de hábitos abrange todas as atividades do Jardim de Infância;

Os hábitos devem ser adquiridos gradativamente em situações reais;

Deve a criança aprender a sentar-se corretamente para evitar deformações na coluna vertebral, e defeitos na visão;

Deve habituar a criança a usar as formas de cortesias: obrigado, com licença, bom dia, boa tarde, adeus...

(REVISTA DO ENSINO/RS, nº 55, set. 1958, p. 41)

O periódico, de forma recorrente, busca esclarecer as professoras sobre os hábitos a desenvolver e a evitar entre as crianças. No número 4 (mar. 1952) é publicada uma extensa lista de atitudes às quais a jardineira deveria estar atenta: caminhar sem 
bater com os pés; não interromper as pessoas que falam; não falar na hora do repouso; não empurrar, nem bater nos colegas; saber respeitar os pais e a jardineira; não falar com a boca cheia; beber sem ruído, evitando entornar a água; usar o guardanapo e o lenço de maneira conveniente; dobrar guardanapos, toalhas e lenços; lavar as mãos à hora das refeições (p. 26). Dez anos depois, novamente um lembrete dos hábitos a evitar nas crianças: falar quando o outro fala; falar alto; empurrar os outros ao passar num lugar apertado ou ao se colocar em forma; querer passar à frente; jogar papéis no chão; caminhar batendo ou arrastando os pés; fazer barulho na hora do repouso; arrastar as cadeiras (REVISTA DO ENSINO/RS, nº 75, abr. 1961, p. 42).

Para chamar a atenção das professoras e dos pais, a revista publica, ao lado da subseção "Da Jardineira para a Jardineira", um decálogo às avessas sobre "Como educar mal uma criança", escrito por um professor americano, não identificado: darem presentes sempre que pedir; elogiarem muita a criança; falarem da criança diante dela; os pais se desrespeitarem diante dela; não a vigiem durante as brincadeiras e as refeições, darem castigos por nada e rirem de seus defeitos, não marcarem horas certas para brincar, comer e dormir (REVISTA DO ENSINO/RS, maio/jun. 1956, n. 47, p. 18).

O último “Da Jardineira para a Jardineira”, publicado na revista (n 93, jun.1963, p. 22), reforça, mais uma vez, os objetivos do Jardim de Infância: “formar na criança hábitos de sociabilidade, de disciplina, cooperação, polidez, ordem, higiene, responsabilidade, respeito, pontualidade, independência, cooperação". Para atingir esses objetivos, a professora deve ter "sólidos conhecimentos de psicologia infantil e de didática especial", os quais são também fornecidos nos textos teóricos que acompanham a seção de educação pré-primária - "a missão de jardineira não é instruir, mas educar, criar hábitos com suavidade e fineza" (REVISTA DO ENSINO/RS, n 82, abr. 1962, p. 18).

Entre as atividades esperadas da professora jardineira estava a organização de uma Associação de Mães ou Clube de Mães, a qual deveria funcionar anexa à escola. Essa iniciativa tinha a função de aproximar a escola e a família, e, consequentemente, mãe e educadora. É interessante ressaltar o entendimento de família, restrito à mãe. Isso decorre do fato de que nessas décadas uma grande parcela das mulheres eram "donas de casa", não exercendo funções de trabalho formal. O convívio diário entre professora e mãe era considerado fundamental para o "desenvolvimento harmonioso e integral". 
Além disso, também deveria organizar reuniões mensais, que poderiam ser dirigidas pela diretora da escola ou pela professora. Os temas sugeridos envolviam conhecimentos, objetivos e realizações do Jardim de Infância, recomendações de higiene infantil, conselhos relativos à alimentação, e, por fim, assuntos educacionais, os quais não estão explicitados (REVISTA DO ENSINO/RS, nº 38, set. 1957, p. 11).

O brincar e os brinquedos são temas sempre presentes na seção Educação Préprimária, assim como os lembretes, os quais abordam a necessidade de a professora estar atenta durantes essas atividades, especialmente, “observar seus alunos na hora do jogo, onde eles se mostram, aprendem regras para viverem em sociedade" (REVISTA DO ENSINO/RS, $n^{\circ} 79$, out. 1961, p. 19).

Muito significativo é o lembrete que sinaliza à professora jardineira que "a criança que frequenta o Jardim de Infância deve ignorar que está sendo educada e aprendendo, deve pensar que está somente brincando". Para enfatizar essa premissa, a revista publica o artigo de Heloísa Marinho", intitulado “Vida e Educação no Jardim de Infância”, em que a autora destaca a observação de Lourenço Filho, "a iniciação prematura da leitura e da escrita atrasa a aprendizagem, por roubar à criança o tempo necessário às atividades lúdicas, preparação essencial à vida". Além disso, a autora relata que a pesquisa realizada no Rio de Janeiro "comprovou que crianças provenientes de Jardim de Infância, cujo programa não abrangia nenhuma tentativa de alfabetização, tiveram no fim da primeira série taxa de aprovação superior aos demais" (REVISTA DO ENSINO/RS, nº 57, nov. 1958, p. 24).

Na década de 1950 e 1960, esta preocupação decorre dos baixos índices de alfabetização na educação primária, sendo a educação pré-primária entendida como educação compensatória, para adaptar as crianças às exigências do próximo nível de escolarização. Dessa forma, o periódico busca chamar a atenção das professoras para a função da educação pré-primária. O artigo de Angelina Rocha de Assis, diretora de um Jardim de Infância em Salvador/Bahia, intitulado "A Aprendizagem da leitura e da escrita e o Jardim de Infância”, assinala que muitas escolas pré-escolares estavam desvirtuando suas funções. Baseada em "princípios educacionais modernos”, que avançam de Fröebel

\footnotetext{
${ }^{9}$ Heloisa Marinho (1903-1994). Professora catedrática do Instituto de Educação do Rio de Janeiro. Autora da obra "Vida e Educação no Jardim de Infância" (Rio de Janeiro: Editora Noite, 1952). Sobre, ver LEITE FILHO (2011).
} 
e Montessori, destaca que a significação desse nível de ensino é: "revelar habilidades, aptidões, acompanhar iniciativas, equilibrar incertezas e estimular a crianças em suas experiências". E acrescenta: "zela pela saúde da criança dentro de normas higiênicas, no que se refere à alimentação, distribuindo merenda saudável e nutritiva, prestando-lhe assistência médica e dentária" (REVISTA DO ENSINO/RS, nº 56, ago. 1958, p. 23). No entanto, o lembrete, publicado em abril de 1962, enfatiza o contar e ler histórias para as crianças, pois "desenvolve o grau de atenção e vocabulário, preparando o terreno para a alfabetização" (REVISTA DO ENSINO/RS, n 82, abr. 1962, p. 18).

Nesse sentido, o conjunto das matérias publicadas na seção Educação-Primária tinha por meta instrumentalizar a professora jardineira com as ferramentas necessárias para exercer o seu ofício, o qual se destinava a preparar as crianças, que completassem os três períodos do Jardim de Infância, a ter as condições necessárias à aprendizagem da leitura e da escrita na escola primária. As habilidades elencadas eram: coordenação motora, ouvir e ver com atenção, expressar com clareza seus pensamentos, pronunciar corretamente as palavras de uso comum, saber distinguir semelhanças e diferenças, manejar com destreza o lápis para a escrita (REVISTA DO ENSINO/RS, nº 73, nov. 1960, p. 43).

\section{Finalizando}

Analisar o que se escrevia e se publicava sobre a educação infantil, nas décadas de 1950 e 1960, na Revista do Ensino/RS, objetiva perceber como se processava a formação continuada das professoras jardineiras, em nível pós-secundário, e em serviço. As atividades didático-pedagógicas recomendadas remetem para compreensão do processo de transformação da ideia de educação da infância e de conformação de práticas educativas e saberes escolares na instituição pré-escolar - Jardim de Infância, que se expandia no país. Às professoras de educação infantil hoje, em formação e em serviço, permite que compreendam como historicamente se processa a construção indentitária profissional de seu campo de atuação. 
Kuhlmann Jr (1998, p. 163), ao analisar a "Revista Jardim de Infância” (1896-1897) da Escola Normal Caetano de Campos de São Paulo ${ }^{10}$, assinala que a mesma "inaugura um método de ditar um receituário às professoras de educação infantil". Nessa mesma direção, observa-se que a Revista do Ensino/RS mantém essa dimensão disciplinadora do cotidiano das professoras jardineiras, assim como, direciona e busca homogeneizar as atividades didático-pedagógicas a serem aplicadas. A figura da mulher "jardineira" também se aproxima do que o autor chama de "infantilizar a professora”, muitas vezes, dirigindo-se a ela com expressões no diminutivo, como se fosse a criança. O deve ser enfatiza um comportamento exemplar e conhecimentos científicos em várias áreas do conhecimento.

Assim, o estudo do impresso permite analisar a historicidade do processo discursivo, que idealiza a figura do professor e de seu fazer cotidiano; produz, com isso, uma maneira de pensar sobre a educação brasileira, a partir das imagens de realidade educacional que passaram para os leitores. A revista, falando de professor para professor, através de um discurso idealizador e idealizado - moralizador, formador da sua postura individual e social -, objetiva cristalizar, pela sacralização da função docente, determinadas práticas e crenças quanto à sua conduta. O projeto editorial fará uso de diferentes estratégias e mecanismos de persuasão de seu leitor, tecendo e homogeneizando o pensar de uma categoria profissional; perpetuando alguns sentidos em detrimento de outros e produzindo um discurso de construção do leitor-ideal (BASTOS, 1997).

Assim, a análise da historicidade do discurso da Revista do Ensino/RS, referente à educação pré-primária, permite conhecer a retórica de conformação do ser docente, pelo desvelamento do discurso político-ideológico embutido no discurso técnico-pedagógico. Nessa perspectiva, o passado se faz presente, pois possibilita refletir sobre a identidade social forjada e herdada e operar um trabalho de reconstrução histórica da sua formação profissional e prática cotidiana (BASTOS, 1997). Para Hameline (1986, p. 197), o discurso pedagógico é o mais metafórico, o que leva à perpetuação de uma tradição (conservação) e uma lógica de moralização histórica - a ideia da boa consciência pedagógica. A preocupação combinada de selecionar os professores e de (in)formá-los

\footnotetext{
${ }^{10}$ Sobre, ver MONARCHA (1999).
} 
segundo um certo modelo de "bom" professor vem se constituindo historicamente e convergindo para o delineamento da representação da docência em todos os níveis de atuação.

Tomando essas premissas, buscamos aproximar o ontem e o hoje da educação infantil. Para tal, é interessante assinalar a perspectiva para esse nível na Base Nacional Comum Curricular/BNCC (BRASIL, 2017), que denota preocupações já presentes na seção analisada. A BNCC recomenda que "o brincar é espontâneo, mas que, da parte do professor faz-se necessária a intencionalidade pedagógica (...), mas que respeite o desenvolvimento de cada criança” (BRASIL, 2017, p. 27). Mas também destaca a necessidade de "mais ênfase nas práticas de leitura e oralidade e experiências de matemática", ao mesmo tempo em que assinala que a "Educação Infantil não é preparatória para o Ensino Fundamental, nem se busca que as crianças tenham práticas prototípicas dessa etapa, mas a aproximação a essas experiências é positiva, sem a necessidade de formalização" (BRASIL, 2017, p. 27-28). Os tempos são outros, mas as preocupações substanciais denotam uma longa duração em torno da escolarização préprimária, os quais estão presentes na formação de professores, nos seus propósitos e finalidades, na orientação de atividades, problematizando questões relativas à autonomia e articulação com a educação primária.

\section{Referências}

BRASIL. Ministério da Educação. Secretaria da Educação Básica. Base Nacional Comum Curricular: relatório final sobre o processo de elaboração das versões 1 e 2 . Belo Horizonte: Centro de Alfabetização Leitura Escrita/CEALE - Faculdade de Educação da Universidade Federal de Minas Gerais, 2017. 202 p.

BASTOS, Maria Helena Camara. As revistas pedagógicas e a atualização do professor: A Revista do Ensino do Rio Grande do Sul (1951-1992). In: CATANI, D.; BASTOS, M.H.C. (Orgs.). Educação em revista: a imprensa periódica e a história da educação. São Paulo: Escrituras, 1997. p. 47 a 76.

BASTOS, Maria Helena Camara. A Revista do Ensino do Rio Grande do Sul (1939 - 1942): O Novo e o Nacional em Revista. Pelotas: SEIVA, 2005.

BASTOS, Maria Helena Camara; COLLA, Anamaria Lopes. A idealização do professor na representação da docência: Retratando mestres In: ABRAHÃO, Maria Helena Menna Barreto (Org.). A Aventura (Auto)biográfica. Porto Alegre/RS: Edipucrs, 2004. p. 465-484. 
BASTOS, Maria Helena Camara; LEMOS, Elizandra Ambrósio; BUSNELLO, Fernanda Bastani. Pedagogia da Ilustração. Uma face do impresso. In: BENCOSTTA, Marcus Levy Albino (Org.) Culturas escolares, saberes e práticas educativas: itinerários históricos. São Paulo: Cortez editora, 2007. P. 41-78.

BASTOS, Maria Helena Camara. Infância, Escola e Civilidade: Os Jardins de Infância de Gisela Schmeling (Porto Alegre/RS, 1948-1971). Investigar, Intervir e Preservar: Caminhos da História da Educação Luso-Brasileira. In: CONGRESSO LUSO-BRASILEIRO DE HISTÓRIA DA EDUCAÇÃO, XI, Porto (PT), 2016. Anais... Porto/PT: CITCEM, 2016.

HAMELINE, Daniel. L'éducation, ses images et son propos. Paris: Ed. ESF, 1996.

KOIRE, Martha. Requisitos para uma Professora de Jardim de Infância. Revista do Ensino. $N^{\circ} 76$, maio 1961, p. 33-34.

KUHLMANN Jr, Moysés. Infância e educação infantil: uma abordagem histórica. Porto Alegre: Mediação, 1998.

LEITE FILHO, Aristeo Gonçalves. História da Educação Infantil: Heloisa Marinho: uma tradição. São Paulo: De Petrus, 2011.

LOURO, Guacira Lopes. Prendas e anti-prendas: uma história da educação feminina no Grande do Sul. 1986. 273f. Tese (Doutorado em Educação na Área de Filosofia e História da Educação) - Universidade Estadual de Campinas, Faculdade de Educação, , Campinas, 1986.

MONARCHA, Carlos. A Escola Normal da Praça: o lado noturno das luzes. Campinas: Unicamp, 1999.

PERES, Eliane Teixeira. Aprendendo formas de pensar, de sentir e de agir - a escola como oficina da vida: discursos pedagógicos e práticas escolares da escola pública primária gaúcha (1909-1959)., 2000. Tese (Doutorado em Educação) - UFMG, Belo Horizonte, 2000.

QUADROS, Claudemir de. Centro de pesquisas e Orientação Educacional - CPOE/RS: discursos e ações institucionais. 2005. Projeto de Tese (Doutorado em Educação) UFRGS, Porto Alegre, 2005.

RS. Secretaria de Educação e Cultura. Revista do Ensino. Porto Alegre: s/ed, 1951-1978. SEÇÃO Educação Pré-primária. REVISTA DO ENSINO/RS, n. 4, mar. 1952, p. 26)

SCHAFFER, Camila; BASTOS, M.H.C. A Educação Pré-Primária na Revista do Ensino RS (1951-1978): entre imagens e discursos. Porto Alegre: PUCRS/FAPERGS, 2007. Relatório de Pesquisa Bolsa de Iniciação Científica FAPERGS. mimeo 9 p.

SCHMELING, Gisela. 10 Mandamentos para uma Jardineira. Revista do Ensino/RS, n. 11, p.19, nov.1952. 
SOUZA, Jane Felipe de. Governando mulheres e crianças: jardins de infância em Porto Alegre na primeira metade do século XX. 2000. 201 p. Tese (Doutorado em educação) UFRGS/ PPEDU, Porto Alegre, 2000.

Quadro 1: De Jardineira para Jardineira

\begin{tabular}{|c|c|c|}
\hline Número & Mês e Ano & Tema \\
\hline 36 & Mar.1956 & Depois do recreio, o repouso \\
\hline 37 & Abr. 1956 & Você não esqueceu \\
\hline 38 & Mai/jun.1956 & $\begin{array}{c}\text { Vocabulário acessível à criança.... } \\
\text { O Brincar }\end{array}$ \\
\hline 39 & Ago.1956 & O Desenho \\
\hline 40 & Set. 1956 & Contar Histórias \\
\hline 41 & $\begin{array}{c}\text { Out/nov. } \\
1956\end{array}$ & Trabalhos em grupos (socialização) \\
\hline 42 & Mar. 1957 & Autonomia da criança \\
\hline 43 & Abr. 1957 & A reflexão é uma qualidade \\
\hline 44 & Mai. 1957 & Brinquedos \\
\hline 45 & Jun. 1957 & Exercícios sensoriais \\
\hline 46 & Ago. 1957 & Como desenvolver os cinco sentidos \\
\hline 47 & Set. 1957 & Associação ou Clube de Mães \\
\hline 51 & Abr. 1958 & Organização das turmas \\
\hline 52 & Mai. 1958 & Música \\
\hline 53 & Jun. 1958 & Música \\
\hline 55 & Set. 1958 & Formação de hábitos \\
\hline 62 & Ago. 1959 & A Banda Infantil \\
\hline 63 & Set. 1959 & Modelagem \\
\hline 66 & Mar. 1960 & Exame de consciência \\
\hline 68 & Mai. 1960 & Material didático \\
\hline 69 & Jun. 1960 & Modelagem \\
\hline 70 & Ago. 1960 & Pintura com dedo \\
\hline 71 & Set. 1960 & A integração da criança no grupo \\
\hline 72 & Out. 1960 & Blocos de construção e jogos de armar \\
\hline 74 & Mar. 1961 & A Educação física no período pré-primário \\
\hline 76 & Mai. 1961 & As qualidades da jardineira quanto à voz \\
\hline 77 & Ago. 1961 & O Brincar \\
\hline 78 & Set. 1961 & Como ensinar através de situações reais \\
\hline 79 & Out. 1961 & O Brincar \\
\hline 82 & Abr. 1962 & Missão da jardineira \\
\hline 83 & Mai. 1962 & Matemática \\
\hline 85 & Jun. 1962 & A linguagem no Jardim de Infância \\
\hline 93 & Jun. 1963 & Hábitos de civilidade \\
\hline
\end{tabular}

Fonte: Revista do Ensino/RS (mar. 1956 a jun. 1963) 
Recebido em: 02/07/2017 Aprovado em: 06/09/2017

Universidade do Estado de Santa Catarina - UDESC Programa de Pós-Graduação em Educação - PPGE

Revista Linhas

Volume 18 - Número 38-Ano 2017

revistalinhas@gmail.com 